\title{
Evaluation of Entrance Skin Radiation Exposure Dose for Pediatrics Examined by Digital Radiography at Asser Central Hospital-KSA
}

\author{
Sami Nasreldein Abdelwally Eljak ${ }^{1}$, Caroline Edward Ayad ${ }^{2 *}$, Elsafi Ahmed Abdalla ${ }^{2}$ \\ ${ }^{1}$ Radiology Department, Asser Central Hospital, Saudi Arabia, Saudi \\ ${ }^{2}$ College of Medical Radiological Science, Sudan University of Science and Technology, Khartoum, Sudan \\ Email: ${ }^{*}$ carolineayad@yahoo.com
}

Received 27 May 2015; accepted 19 July 2015; published 23 July 2015

Copyright (C) 2015 by authors and Scientific Research Publishing Inc.

This work is licensed under the Creative Commons Attribution International License (CC BY).

http://creativecommons.org/licenses/by/4.0/

(c) (i) Open Access

\begin{abstract}
Assessment of entrance skin doses for patients in Digital radiography examinations should be made as a means for the optimization of the radiation protection of the patients. We measured the entrance skin dose (ESD) received by 50 pediatrics undergoing 12 types of diagnostic X-ray examination at Radiology Department of Asser Central Hospital-KSA. The entrance skin dose ESD was determined via measurements parameters: focus to skin distance (FSD), tube current (mAs) and tube voltage $(\mathrm{kV})$ in arithmetical equation. The mean \pm SD for ESDs were found to be $0.16 \pm 0.03$, $0.21 \pm 0.01,0.63 \pm 0.26,0.55 \pm 0.09,0.15 \pm 0.05,0.27 \pm 0.06,0.41 \pm 0.19,0.46 \pm 0.18,0.46 \pm 0.12$, $0.20 \pm 0.02,0.39 \pm 0.01,0.29 \pm 0.03$, for PA chest, foot, AP pelvis, PA skull, PA hand, AP arm, ankle, AP shoulder, abdomen, forearm, AP femur, AP elbow consequently. Our study is considered as an attempt to evaluate the ESDs received by digital radiographic $x$-ray machine for children aged between 2 - 15 years old, taking in our considerations number of other variables. The mean ESD values obtained are found to be within the standard reference. The data obtained may add to the available information in national records for general use. It may provide guidance on where efforts on dose reduction will need to be directed to fulfill the requirements of the optimization process and serve as a reference for future researches.
\end{abstract}

\section{Keywords}

Entrance Skin Dose, Pediatrics, Digital Radiography

\footnotetext{
${ }^{*}$ Corresponding author.

How to cite this paper: Eljak, S.N.A., Ayad, C.E. and Abdalla, E.A. (2015) Evaluation of Entrance Skin Radiation Exposure Dose for Pediatrics Examined by Digital Radiography at Asser Central Hospital-KSA. Open Journal of Radiology, 5, 125-130. http://dx.doi.org/10.4236/ojrad.2015.53019
} 


\section{Introduction}

In radiology field dose assessment should be made to enhance the optimization of the radiation protection of the patients and to deliver minimum dose to the examinations. Dose measurements are necessary for the fulfillment of the international guidelines and regulations [1].

It is known that children diagnostic radiological examinations have higher risk when compared to the ones carried out for adults. Young individuals have longer life expectancy and their developing tissues are more radiosensitive. The relative risk of harmful effect after radiation exposure during the first 10 years of life is 3 to 4 times if compared to an exposure for 30 or 40 years old [2]. Children have a risk of developing a radiation-induced cancer, because of their greater cell proliferation rate and long life span expectancy [3].

Entrance surface Dose (ESD) is a measure of the radiation dose absorbed by the skin where the X-ray beam enters the patient [1], it have been used to report patient doses, and this has been studied for pediatric patients all over the world [4]. In Saudi Arabia few studies have been carried out in patient radiation concerns, especially with regards to children, moreover work was concerned with calculation of the ESD for pediatric patients undergoing X-ray examinations in a pediatric hospital took place in Taif hospital [5].

Our aim in this study was to measure the entrance skin dose (ESD) for pediatrics undergoing diagnostic X-ray examinations in four hospitals (Asser Central Hospital-Saudi Arabia). To the best of our knowledge, no study was done in the open literature regarding that issues.

\section{Materials and Methods}

\subsection{Selection and Description of Participants}

This prospective study was performed in the period of August 2013 to September 2014. Patients were examined at the radiology department of Asser Central Hospital-Saudi Arabia. Prior to patients examined, a formal approval was obtained from the Ethics and Scientific Committee of this medical center. Informed consents were obtained from patients.

\subsection{Digital Radiography Machine}

(AXIOM Aristos FX/FX Plus system-Siemens). Manufactured for GE Health care, Milwaukee, wi By Siemens, S.N: 4927, Model: ALOIC II, Manufactured: February/2013, Location: Kemnath/Germany, Type: 5234954, Filtration: $2.0 \mathrm{~mm} \mathrm{Al} / 70 \mathrm{KV}$, Localizer Lights: 24 v, $150 \mathrm{~W}$.

\subsection{Parameters and Measuring ESD}

Different radiological examinations including: Foot, AP Pelvis, Skull PA, PA Hand, AP Arm, Ankle, AP Shoulder, Forearm, AP Femur, AP Elbow, were included, these examinations were obtained using fine focus and FFD of $100 \mathrm{~cm}$. Chest PA and Abdomen were obtained by using broad focus and FFD $180-100 \mathrm{~cm}$ respectively. Patient information including age, gender, weight, BMI, height was considered. The type radiological examination and applied projection as well as the exposure details such as tube voltage (KV), tube current (MAS), organ thickness, focal to skin distance (FSD) were evaluated. Data were collected on patient doses during the period from 2013-2014. The ESD was calculated according to the following equation which was applied by (Tung and Tasi; 1999) [6].

$$
\mathrm{ESD}=\mathrm{c}\left(\begin{array}{c}
\mathrm{KVp} \\
\mathrm{FSD}
\end{array}\right)^{2}\left(\begin{array}{c}
\mathrm{mAs} \\
\mathrm{mm} \cdot \mathrm{Al}
\end{array}\right)
$$

where:

ESD stands for Entrance skin dose, $\mathrm{c}=$ constant $=0.2775, \mathrm{Kvp}=$ Applied Tube potential, $\mathrm{mAs}=$ Tube current multiplied by exposure time, FSD = Focus to skin distance, $\mathrm{Al}=$ Aluminum Filtration.

\subsection{Statistical Analyses}

Data were presented as mean \pm SD in a form of comparison tables. Statistical analysis was performed using the standard Statistical Package for the Social Sciences (SPSS Inc., Chicago, IL, USA) version 16. ANOVA and person correlation, Independent t-test were used. Correlation is significant at the $p<0.05$. 


\section{Results and Discussions}

The mean and \pm SD values of all the pediatrics examined in the study were presented in (Table 1). Study population comprised 50 pediatric patients (26 males and 24 females). Pediatric ages ranged from 2 to 15 years; with a mean age of ( $7.19 \pm 3.10)$ years, weight ranged from 21 to $51 \mathrm{Kg}$; with a mean value of (22.31 \pm 7.86$)$ years, mean height of (117.4 \pm 17.36$)$ years, height ranged from 86 to $140 \mathrm{~cm}$; the smallest BMI of the population was 13.2 and the largest value was 26.4.

The mean and \pm SD of the Digital Radiography X-ray machine parameters were presented in (Table 2). The maximum $\mathrm{Kv}$ was found to be 74, mAs of 10, organ thickness $16 \mathrm{~cm}$, Focus to Skin Distance (FSD) of 168.5 and the measured ESD was of 0.92 .

Mean and standard deviation for ESDs in mGy for the radiological examinations were compared with other authors, and were presented in (Table 3), The maximum ESD was found in the AP pelvis $(0.63 \pm 0.26)$ and the minimum dose was found in PA hand $(0.15 \pm 0.05)$. It was found that the dose level received by the digital radiography machine in our hospital were lower than other studies levels [7], [8] with significant difference at $\boldsymbol{p}<$ $\mathbf{0 . 0 0 0}$ in respected to different type of X-ray examinations. The justification may be due to the fact that the digital X-ray machine was manufactured with high engineering technology and gave low doses because of the cathode cup is optimized for use in a line-focus, planar anode tube and has a slot in which the emitter is situated. Table 3 showed that the ESD (mGy) for the PA chest was close to that reported by the (NRPB, 2000) [8] mGy, but lower than the value of European Commission [7] by 0.14 mGy. The ESD (mGy) for the AP pelvis was lower than the value that reported by European Commission [7] by $3.7 \mathrm{mGy}$ may be due to the patients thickness under study. The ESD (mGy) for abdomen half than value recorded by the European Commission [7] and close to that values reported by National Radiological Protection Board [8] and (IAEA, 1996) [9].

Similar examinations carried out in Sudan at four hospitals, eight X-ray units, their hospital mean ESDs estimated range from 0.17 to $0.27 \mathrm{mGy}$ for chest AP, 1.04 - 2.26 mGy for Skull AP/PA [10].

The radiological technique including AP, Dorsi planter, lateral and oblique projections have no impact on the ESDs measures it ranged between 0.15 - 0.33 mGy Dorsi planters and oblique have less ESD than other projections (Table 4).

The maximum pediatric age class was found at ages between 6 - 9 years, they constituting 23 pediatric patients. The maximum ESD received was for pediatric of ages of 10 and more; however there is no significant relation between age classes and ESD (Table 5).

Table 1. Pediatrics demographic data.

\begin{tabular}{ccccc}
\hline & Age/years & Weight/Kg & BMI & Height/cm \\
\hline Mean & 7.19 & 22.31 & 15.76 & 117.44 \\
Median & 7.25 & 23.00 & 15.20 & 124.00 \\
Std. Deviation & \pm 3.10 & \pm 7.86 & \pm 2.17 & \pm 17.36 \\
Minimum & 2.0 & 12.00 & 13.20 & 86.00 \\
Maximum & 15.0 & 51.00 & 26.40 & 140.00 \\
\hline
\end{tabular}

Table 2. Mean and standard deviation of the digital radiography X-ray machine.

\begin{tabular}{|c|c|c|c|c|c|}
\hline & $\begin{array}{c}\text { Tube Voltage } \\
\text { (Kv) }\end{array}$ & $\begin{array}{c}\text { Tube Current } \\
\text { (mAs) }\end{array}$ & $\begin{array}{c}\text { Organ } \\
\text { Thickness }\end{array}$ & $\begin{array}{l}\text { Focus to Skin } \\
\text { Distance (FSD) }\end{array}$ & $\begin{array}{c}\text { Entrance Skin } \\
\text { Dose (ESD) }\end{array}$ \\
\hline Mean & 63.76 & 5.32 & 7.01 & 103.59 & 0.33 \\
\hline Median & 65.00 & 5.50 & 5.00 & 96.00 & 0.29 \\
\hline Std. Deviation & \pm 5.98 & \pm 1.94 & \pm 4.19 & \pm 24.69 & \pm 0.18 \\
\hline Minimum & 48.00 & 2.00 & 2.00 & 85.00 & 0.11 \\
\hline Maximum & 74.00 & 10.00 & 16.00 & 168.50 & 0.92 \\
\hline
\end{tabular}


Table 3. Mean and standard deviation for ESDs in mGy for the radiological examinations were compared with other authors.

\begin{tabular}{|c|c|c|c|c|c|c|c|}
\hline \multicolumn{6}{|c|}{ Entrance Skin Dose (ESD) } & \multicolumn{2}{|c|}{ Other Authors } \\
\hline & $\mathbf{N}$ & Mean & Minimum & Maximum & $p$-Value & EC, 1996 mGy [7] & NRPB, 2000 mGy [8] \\
\hline Chest PA & 7 & $0.16 \pm 0.03$ & 0.11 & 0.20 & & 0.3 & 0.2 \\
\hline Foot & 2 & $0.21 \pm 0.01$ & 0.21 & 0.21 & & - & - \\
\hline AP Pelvis & 3 & $0.63 \pm 0.26$ & 0.41 & 0.92 & & 10 & 4 \\
\hline Skull PA & 6 & $0.55 \pm 0.09$ & 0.42 & 0.69 & & 5 & 3 \\
\hline PA Hand & 6 & $0.15 \pm 0.05$ & 0.12 & 0.25 & & - & - \\
\hline AP Arm & 5 & $0.27 \pm 0.06$ & 0.17 & 0.32 & & - & - \\
\hline Ankle & 2 & $0.41 \pm 0.19$ & 0.27 & 0.55 & 0.000 & - & - \\
\hline AP Shoulder & 3 & $0.46 \pm 0.18$ & 0.29 & 0.64 & & - & - \\
\hline Abdomen & 6 & $0.46 \pm 0.12$ & 0.29 & 0.62 & & 10 & - \\
\hline Forearm & 4 & $0.20 \pm 0.02$ & 0.19 & 0.22 & & - & - \\
\hline AP Femur & 2 & $0.39 \pm 0.01$ & 0.39 & 0.41 & & - & - \\
\hline AP Elbow & 4 & $0.29 \pm 0.03$ & 0.28 & 0.34 & & - & - \\
\hline Total & 50 & $0.33 \pm 0.18$ & 0.11 & 0.92 & & & - \\
\hline
\end{tabular}

Table 4. Mean and standard deviation for ESDs in mGy according to the radiological technique.

\begin{tabular}{ccccccc}
\hline & \multicolumn{7}{c}{ Entrance Skin Dose (ESD) } & & M-Value \\
\hline AP & N & Mean & Std. Deviation & Minimum & Maximum & 0.919 \\
Dorsi Planter & 30 & 0.37 & \pm 0.20 & 0.113 & 0.214 & 0.105 \\
Lateral & 4 & 0.15 & \pm 0.04 & 0.120 & 0.547 & 0.163 \\
Oblique & 15 & 0.33 & \pm 0.13 & 0.136 & 0.919 \\
Total & 1 & 0.16 & \pm 0.0 & 0.113 & \\
\hline
\end{tabular}

Table 5. Mean and standard deviation for ESDs in mGy according to the pediatrics ages.

\begin{tabular}{ccccccc}
\hline & \multicolumn{7}{c}{ Entrance Skin Dose (ESD) } & M-Value \\
\hline Age/Years & N & Mean & Std. Deviation & Minimum & Maximum & 0.693 \\
2 - 5 y & 16 & 0.29 & \pm 0.17 & 0.120 & 0.630 & 0.344 \\
$6-9$ y & 23 & 0.34 & \pm 0.17 & 0.113 & 0.919 & 0.919 \\
$\geq 10$ y & 11 & 0.39 & \pm 0.23 & 0.157 & 0.113 & \\
Total & 50 & 0.33 & \pm 0.18 & & \\
\hline
\end{tabular}

Gender and body characteristics including weight, height, BMI, had no impact on the ESDs, however the organ thickness had a significant relation with ESD at $p<0.000$ (Table 6 and Table 7). Correlations between Entrance Skin Dose (ESD) and exposure parameters showed significant relation (Table 8). Many authors stated that the absorbed dose in skin is directly proportional to tube current; the length of exposure, and the square of peak kilovoltage [11]. Our justification was that the digital imaging X-ray machine may allow for use of a lower tube current or a shorter exposure, thus reducing the dose to the patient as mentioned previously [11] and where the image quality controlled automatically because the using of automatic exposure control as well as the presence of aluminum filter of $2.0 \mathrm{~mm}$. 
Table 6. Mean and standard deviation for ESDs in mGy according to gender.

\begin{tabular}{|c|c|c|c|c|c|c|}
\hline \multicolumn{6}{|c|}{ Entrance Skin Dose (ESD) } & \multirow{2}{*}{$p$-Value } \\
\hline Gender & $\mathbf{N}$ & Mean & Std. Deviation & Minimum & Maximum & \\
\hline Male & 26 & 0.32 & \pm 0.19 & 0.122 & 0.693 & \multirow{3}{*}{0.549} \\
\hline Female & 24 & 0.35 & \pm 0.18 & 0.113 & 0.919 & \\
\hline Total & 50 & 0.33 & \pm 0.18 & 0.113 & 0.919 & \\
\hline
\end{tabular}

Table 7. Correlation between the Entrance Skin Dose (ESD) and the pediatrics body characteristics.

\begin{tabular}{lcc}
\hline \multicolumn{2}{c}{ Correlations between the Entrance Skin Dose (ESD) and the Pediatrics Body Characteristics } \\
\hline Weight/Kg & Pearson Correlation & 0.064 \\
& Sig. (2-tailed) & 0.657 \\
& $\mathrm{~N}$ & -0.175 \\
BMI & Pearson Correlation & 0.224 \\
& Sig. (2-tailed) & 50 \\
& $\mathrm{~N}$ & 0.189 \\
Height & Pearson Correlation & 0.189 \\
& Sig. (2-tailed) & 50 \\
& $\mathrm{~N}$ & $0.364^{* *}$ \\
Organ Thickness & Pearson Correlation & 0.009 \\
\end{tabular}

*Correlation is significant at the 0.05 level (2-tailed). ${ }^{* *}$ Correlation is significant at the 0.01 level (2-tailed).

Table 8. Correlation between the Entrance Skin Dose (ESD) and exposure parameters

\begin{tabular}{ccc}
\hline \multicolumn{2}{c}{ Correlations between Entrance Skin Dose (ESD) and Exposure Parameters } \\
\hline Tube Voltage (KV) & Pearson Correlation & $0.351^{*}$ \\
& Sig. (2-tailed) & 0.013 \\
Tube Current (MAs) & Pearson Correlation & $0.709^{* *}$ \\
& Sig. (2-tailed) & 0.000 \\
Focus to Skin Distance (FSD) & Pearson Correlation & $-0.491^{* *}$ \\
Total Number & Sig. (2-tailed) & 0.000 \\
\hline
\end{tabular}

${ }^{*}$ Correlation is significant at the 0.05 level (2-tailed). ${ }^{* *}$ Correlation is significant at the 0.01 level (2-tailed).

However, the risk from radiation exposure of the patients must be balanced versus the diagnostic benefit. Many departments do not use recommended radiographic parameters for children using digital radiography, furthermore, wide variations in the applications of the radiographic techniques, equipment performance at different hospitals over the world.

\section{Conclusion}

Our study in Saudi Arabia at Asser Central Hospital-KSA is considered as an attempt to evaluate the ESDs re- 
ceived by digital radiographic X-ray machine for children aged between 2 - 15 years old, taking in our considerations number of other variables. For all the examinations studied in the hospital, the mean ESD values obtained are found to be within the standard reference values of doses. The data obtained may add to the available information in national records for general use. It will provide guidance on where efforts on dose reduction will need to be directed to fulfill the requirements of the optimization process and serve as a reference for future researches and in pediatrics of ages less than two years old.

\section{Acknowledgements}

Thanks for Asser Central Hospital-KSA, and Sudan University of Science and Technology, College of Medical Radiological Science, Khartoum, Sudan.

\section{References}

[1] Taha, M.T., Al-Ghorabie, F.H., Kutbi, R.A. and Saib, W.K. (2015) Assessment of Entrance Skin Doses for Patients Undergoing Diagnostic X-Ray Examinations in King Abdullah Medical City, Makkah, KSA. Journal of Radiation Research and Applied Science, 8, 100-103.

[2] United Nations Scientific Committee on Effects of Atomic Radiation. Sources and Effects of Ionizing Radiation. UNSCEAR 2000 Vol. 1, Report to the General Assembly. New York, 2000.

[3] Persliden, J., Helmorot, E., Hjort, P. and Resjo, M. (2004) Dose and Image Quality in Comparison of Analogue and Digital Techniques in Paediatric Urology Examinations. European Radiology, 14, 638-644. http://dx.doi.org/10.1007/s00330-003-2144-9

[4] Osman, H., Elzaki, A., Abd Elgyoum, A. and Abd Elrahim, E. (2014) Evaluation of Radiation Entrance Skin Dose for Pediatrics Chest X-Ray Examinations in Taif. Wulfenia Journal, 21, 60-67.

[5] Osman, H. (2013) Pediatric Radiation Dose from Routine X-Ray Examination Hospital Based Study, Taif Pediatric Hospital. Scholars Journal of Applied Medical Sciences, 5, 511-515.

[6] Tung, C.J. and Tsai, H.Y. (1999) Evaluations of Gonad and Fetal Doses for Diagnostic Radiology. Proceedings of the National Science Council, Republic of China. Part B, Life sciences, 23, 107-113.

[7] European Committee (EC) (1996) European Guidelines on Quality Criteria for Diagnostic Radiographic Images. EUR 16260EN.

[8] National Radiologic Protection Board (2000) National Protocol for Patient Dose Measurements in Diagnostic Radiology. Report of the Working Party of the Institute of Physics Science in Medicine, NRPB, Chilton Didcot.

[9] International Atomic Energy Agency (1996) International Basic Standards for Protection against Ionizing Radiation and for the Safety of Radiation Source. IAEA Safety Series, Vienna.

[10] Suliman, I.I., Abbas, N. and Habbani, F.I. (2007) Entrance Surface Doses to Patients Undergoing Selected Diagnostic X-Ray Examinations in Sudan. Radiation Protection Dosimetry, 123, 209-214. http://dx.doi.org/10.1093/rpd/ncl137

[11] Parry, R.A., Glaze, S.A. and Archer, B.R. (1999) The AAPM/RSNA Physics Tutorial for Residents Typical Patient Radiation Doses in Diagnostic Radiology. Radiographics, 19, 1289-302. 